\title{
Adsorption of Light Hydrocarbons on LTA and FER Zeolites
}

\author{
Fortunato Migliardini $^{{ }^{*}}$, Fabio Iucolano ${ }^{2}$, Domenico Caputo ${ }^{2}$, Pasquale Corbo ${ }^{1}$ \\ ${ }^{1}$ Istituto Motori, National Research Council of Italy, Naples, Italy \\ ${ }^{2}$ Dipartimento di Ingegneria dei Materiali e Della Produzione, University of Naples "Federico II", Naples, Italy \\ Email: *f.migliardini@im.cnr.it
}

Received May 17, 2013; revised June 17, 2013; accepted July 6, 2013

Copyright (C) 2013 Fortunato Migliardini et al. This is an open access article distributed under the Creative Commons Attribution License, which permits unrestricted use, distribution, and reproduction in any medium, provided the original work is properly cited.

\begin{abstract}
This paper reports the results of an experimental study on adsorption of light hydrocarbons on small pore microporous materials. The choice of hydrocarbons studied was affected taking into consideration the application of adsorption processes in removal of light hydrocarbons from exhaust streams of the petrochemical industry and of light-duty gasoline vehicles under cold start conditions (C4 - C5 paraffins and olefins). The materials investigated were 5A and Ferrierite zeolites, characterized by different pore opening and $\mathrm{Si} / \mathrm{Al}$ ratio. Equilibrium isotherm curves at room temperature were determined by a gravimetric method on dehydrated zeolites, while breakthrough curves in dynamic tests were used to evaluate the adsorption properties of hydrated zeolites at low hydrocarbon partial pressure $(0-1 \mathrm{kPa})$ and in experimental conditions close to those of a $\mathrm{HC}$ trap at the engine exhaust. The experimental results regarding the adsorption capacities were discussed with the aim to understand how the physico-chemical characteristics of the adsorbent material could affect its trapping capability in adsorbing different types of hydrocarbons.
\end{abstract}

Keywords: Hydrocarbon Adsorption; Hydrocarbon Trap; Ferrierite; Linde 5A; Engine Cold Start Emissions

\section{Introduction}

The adsorption processes are widely employed for light hydrocarbons (HC) capture in applications that require the recovery of these compounds in high purity (petrochemical industry) $[1,2]$ and have been recently proposed for the abatement of organic pollutants at the exhaust of light-duty gasoline vehicles under cold start conditions [3].

This last application is justified by the future legislative limits for passenger car emissions in EU and USA that will become more and more stringent and will require the development of new technological solutions, including more effective after-treatment devices. It is known that the largest fraction (more than $80 \%$ ) of the total organic pollutants flows out during the short time following the engine startup (200 seconds). During this period the air/fuel ratio is on the rich side, which implies more $\mathrm{HC}$ emissions, while the temperature of the threeway catalyst (TWC) is lower than its light-off value (473 - $573 \mathrm{~K}$ ), which requires between 60 to $120 \mathrm{~s}$ to be reached. This means that the compliance with the targets set by the incoming legislation will demand a strong

${ }^{*}$ Corresponding author. abatement of hydrocarbon emissions in the cold-start phase [4]. On the other hand, the incoming diffusion of hybrid vehicles increases the importance of the cold-start emissions control, since the number of start-up phases is more frequent in these types of vehicles with respect to conventional ones.

The combination of adsorption traps with catalytic conversion for $\mathrm{HC}$ emission control during the cold start phase of gasoline vehicles has been proposed in several patents [5]. These traps are constituted by a bed of adsorbent material which is able to catch hydrocarbons until the working temperature of the catalytic converter is reached. When the temperature of the exhaust gas increases, trapped hydrocarbons are desorbed and oxidized in the TWC. If the desorption temperature is lower than the light-off catalyst temperature, some hydrocarbons are not oxidized and escape from the tailpipe.

Differently from other commercial adsorbents with high surface area (activated carbons and clays, inorganic gels), zeolites, which are crystalline aluminosilicates, have pores of uniform and molecular size (3 - $10 \AA)$, uniquely determined by the unit structure of the crystal. As a consequence these microporous materials have a high internal surface area (generally higher than $400 \mathrm{~m}^{2} / \mathrm{g}$ ) available 
for adsorption due to channels that uniformly penetrate the entire volume of the solid [6].

This material, which exists in both natural and synthetic form, characterized by different pore opening and $\mathrm{Si} / \mathrm{Al}$ ratio, has been the object of many studies related with $\mathrm{HC}$ trapping, since a particular zeolitic material can be selected as a function of the type of $\mathrm{HC}$ to be trapped and of the particular gaseous environment they have to be removed from [7-11].

In this paper the adsorption of different HCs was studied taking into consideration those compounds which need to be recovered in petrochemical applications, and are present in significant concentration at the exhaust of light-duty gasoline vehicles, typically C4 - C5 paraffins and light olefins. Due to the small molecular size of $\mathrm{HC}$ considered, Ferrierite (FER) and 5A (LTA) zeolites, characterized by pore opening ranging from 3.5 to $5 \AA$ [ [12, 13], were examined as adsorbent materials. The evaluation of adsorption properties was affected by equilibrium isotherms and dynamic tests in flow micro-reactor at room temperature.

\section{Experimental}

All adsorption measurements presented in this paper were performed on commercial zeolitic materials in powder form reported in Table 1. 5A and Ferrierite were studied in order to evaluate the effect of small pore channel structure on adsorption properties of small size HC molecules.

Adsorption isotherms at room temperature were acquired for ethane, ethylene, n-butane, isobutane and isobutene. They were obtained by a gravimetric technique, and performed with the apparatus sketched in Figure 1. This is a McBain-type adsorption balance, equipped with a quartz spring (Ruska Instrument Co., Houston, Texas), whose elongation law is known. A small quartz pan, containing the adsorbent material, hooked to the spring, enables the evaluation of the amount of adsorbate by measuring spring elongation with the help of a cathetometer. Equilibrium gas pressure was measured through electronic devices (Edwards Datametrics 1500). A Heto thermostating unit allowed a temperature control within the range of $\pm 0.1 \mathrm{~K}$. Before measurement samples were thermally activated at $623 \mathrm{~K}$ under high vacuum $(\mathrm{P}<10$ - $6 \mathrm{kPa}$ ) for 3 hours (Edwards Diffstak MK2 diffusion pump).

Table 1. Zeolitic materials used for adsorption tests.

\begin{tabular}{cccc}
\hline Sample & Form & Si/Al & Pore opening, $\AA$ \\
\hline 5A (LTA) & Powder & 1 & $4.2^{*}$ \\
Ferrierite (FER) & Powder & 10 & $\begin{array}{c}4.2 \times 5.4^{* *} \\
3.5 \times 4.8^{* *}\end{array}$ \\
\hline
\end{tabular}

*Ref. [12]; ${ }^{* *}$ Ref. [13].

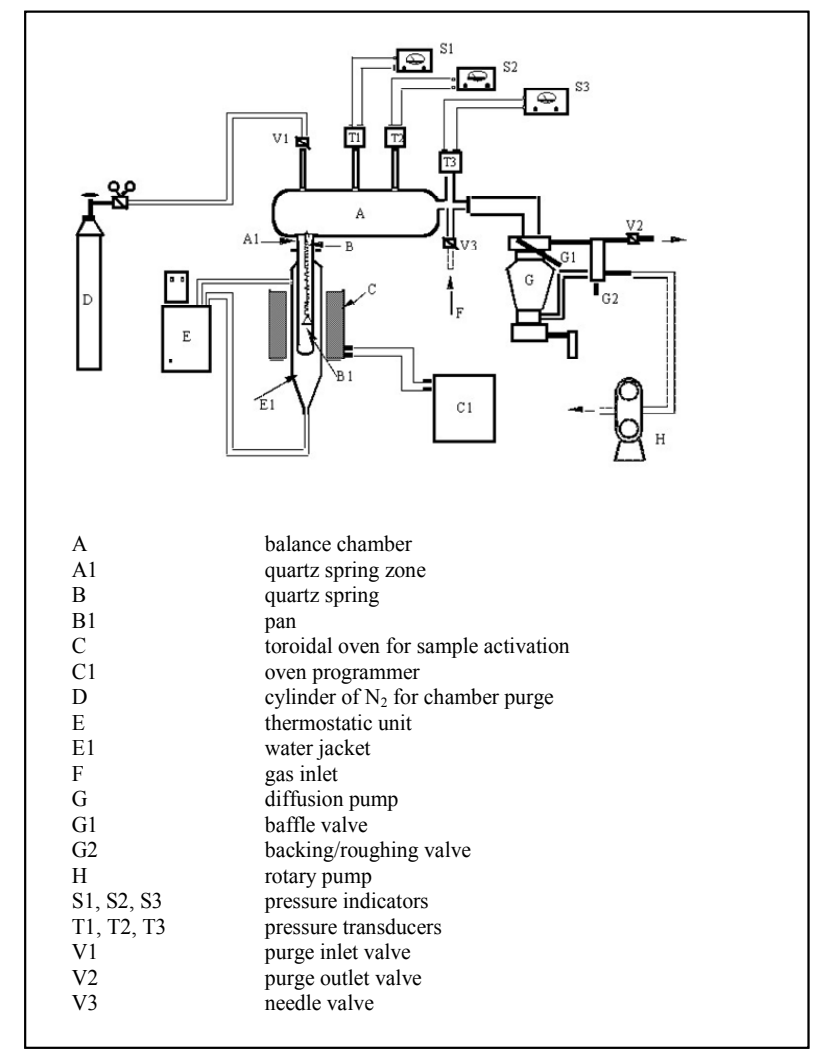

Figure 1. Scheme of the experimental apparatus used for measurements of equilibrium isotherms by gravimetric tests.

After cooling to $298 \mathrm{~K}$ aliquots of gas were allowed from time to time to enter the balance chamber and sufficient time was awaited to attain equilibrium. Adsorption isotherms were outlined by plotting the amounts of adsorbate on dry basis versus gas partial pressures at equilibrium.

Breakthrough curves were determined with the aim to obtain quantitative indications about the adsorption instantaneous capacities and equilibria values at low hydrocarbon partial pressures $(0-1 \mathrm{kPa})$, usually encountered in engine exhaust gases, and to simulate the behavior of a $\mathrm{HC}$ trap working at the engine exhaust. Ethylene was selected as the olefin present in major concentration in exhaust gases of a gasoline engine, together with a mixture of C4 - C5 paraffins.

These adsorption tests were performed by the experimental apparatus shown in Figure 2.

A fixed bed microreactor, constituted by a stainless steel tube of $10 \mathrm{~mm}$ i.d., was inserted in a tubular electric oven equipped with a temperature controller. The reactor was loaded with zeolites in powder form $(1 \mathrm{~g}, 180-350$ $\mu \mathrm{m})$. The gas flow rate $(1 \mathrm{l} / \mathrm{min})$ was selected to realise a space velocity value (gas gravimetric flow rate/adsorbent weight) of $30000 \mathrm{~h}^{-1}$, a value representative of the space velocities conditions occurring at the engine exhaust on 


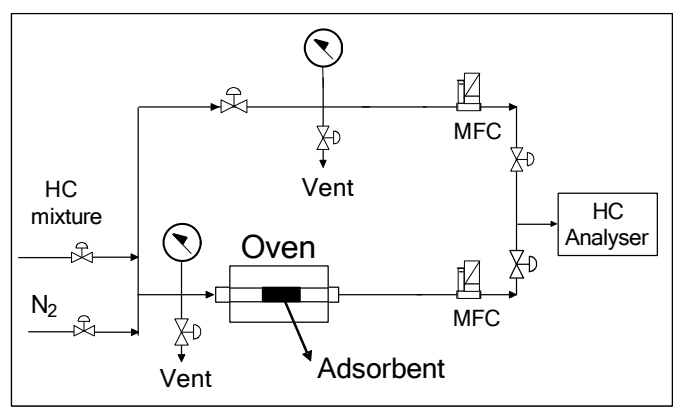

Figure 2. Scheme of the experimental apparatus used for measurements of breakthrough curves.

TWC during automotive start up phase. An on line analyzers equipped with flame ionisation detector (Siemens Fidamat 5 E-AP) was used for hydrocarbon concentration analysis before and after the adsorbent bed.

The breakthrough curves were constructed reporting the ratio of hydrocarbon concentration (expressed as C3 ppm) measured at the outlet of the adsorbent bed and the inlet mixture concentration as function of time on stream $\left(\mathrm{C} / \mathrm{C}_{\mathrm{in}}\right)$. Mixtures of hydrocarbons in nitrogen $(850 \mathrm{ppm}$ expressed as $\mathrm{C} 3$, corresponding to $0.1 \mathrm{kPa}$ ) were fed to the flow microreactor to verify the adsorption properties in experimental condition close to those that could be realized in a HC trap. Taking into account that the adsorption capacity of zeolites is due to a pore filling mechanism, the same concentration of $\mathrm{C} 3$ was used for all mixtures in order to realise comparable carbon mass flow rates in different molecular structures.

The adsorption of light paraffins by breakthrough curves was studied for an equimolar mixture of $\mathrm{C} 4$ - C5 paraffins (n-butane, i-butane, n-pentane, i-pentane, neopentane, total concentration of $850 \mathrm{ppm}$ as $\mathrm{C} 3$ ). The zeolitic materials were tested in all flow adsorption runs without any preliminary thermal treatment, in order to simulate the utilization conditions of a $\mathrm{HC}$ trap at the engine exhaust. In this way each material retained its intra-crystalline water content when it was exposed to hydrocarbon gas stream.

\section{Results and Discussion}

The experimental results of adsorption tests are reported in Figures 3-6, while the equilibrium adsorption capacities at $0.1 \mathrm{kPa}$ and $298 \mathrm{~K}$, expressed as mass of adsorbed HC per $100 \mathrm{~g}$ of zeolite, are summarized in Table 2. The zeolite 5A with pore opening of $4.2 \AA$ (which allows for the passage of molecules with a kinetic diameter of less than $4.9 \AA$ [12]) and $\mathrm{Si} / \mathrm{Al}=1$ was firstly characterised in equilibrium adsorption gravimetric tests at room temperature with different $\mathrm{C} 2$ and $\mathrm{C} 4$ hydrocarbons. In Figure 3 adsorption isotherms of ethylene, ethane, n-butane, isobutane and isobutene at $298 \mathrm{~K}$ on $5 \mathrm{~A}$ are compared.

A magnification of the low pressure zone $(<0.15 \mathrm{kPa})$

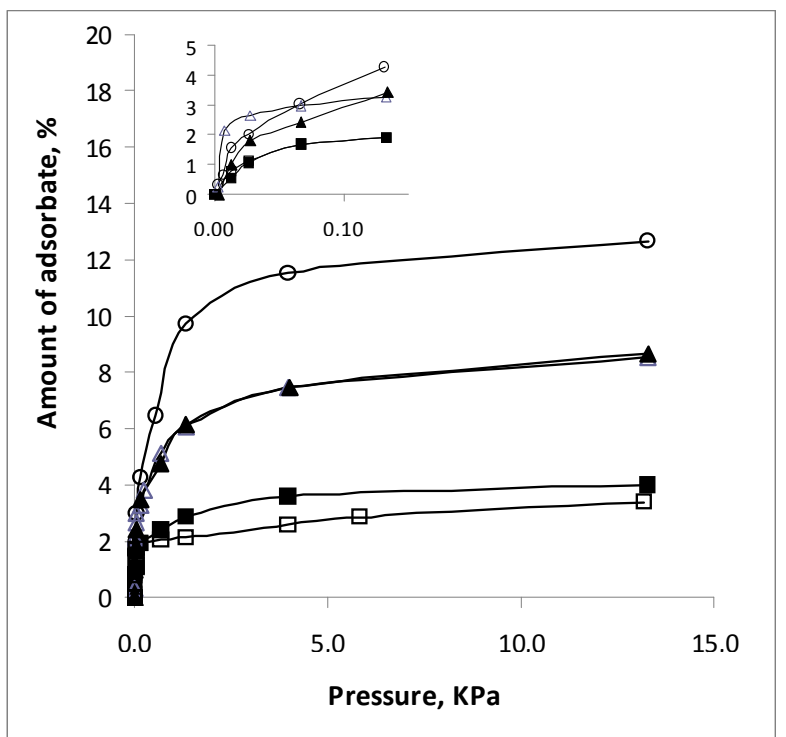

Figure 3. Adsorption isotherms at $298 \mathrm{~K}$ of $\mathrm{n}$-butane $(\circ)$, ethane $(\Delta)$, ethylene $(\Delta)$, isobutane $(\square)$ and isobutene $(\square)$ on zeolite 5A.

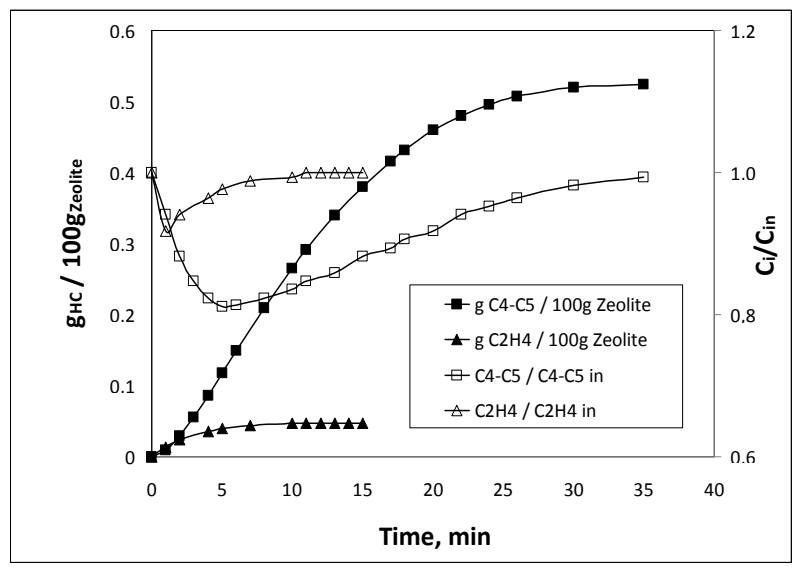

Figure 4. Breakthrough curves (empty symbols) and cumulative adsorption curves (full symbols) at $298 \mathrm{~K}$ for ethylene $(\Delta, \Delta)$ and $\mathrm{C} 4$ - C5 paraffin mixture $(\square, \square)$ on $5 \mathrm{~A}$.

is reported on the top. All curves show the typical shape of the adsorption isotherms on microporous solids [14]. In these conditions $5 \mathrm{~A}$ zeolite showed higher affinity for n-butane and $\mathrm{C} 2$ with respect to ramified $\mathrm{C} 4$ hydrocarbons, with no significant difference between ethane and ethylene. The saturation adsorption values resulted about $12 \%$ for $\mathrm{n}$-butane, $8 \%$ for $\mathrm{C} 2$ and below $4 \%$ for ramified C4. The low adsorption capacity exhibited by zeolite $5 \mathrm{~A}$ for isobutane and isobutene can be attributed to a molecular sieve effect. In fact, the molecular size of these hydrocarbons $(5.5-5.6 \AA)$ is larger than the pore opening of zeolite $5 \mathrm{~A}$ ( $4.2 \AA$, see Table 1). In the hypothesis that adsorption of hydrocarbons on zeolites at $298 \mathrm{~K}$ is essentially due to physical interaction between gas molecule and solid surface (van der Waals interaction) 


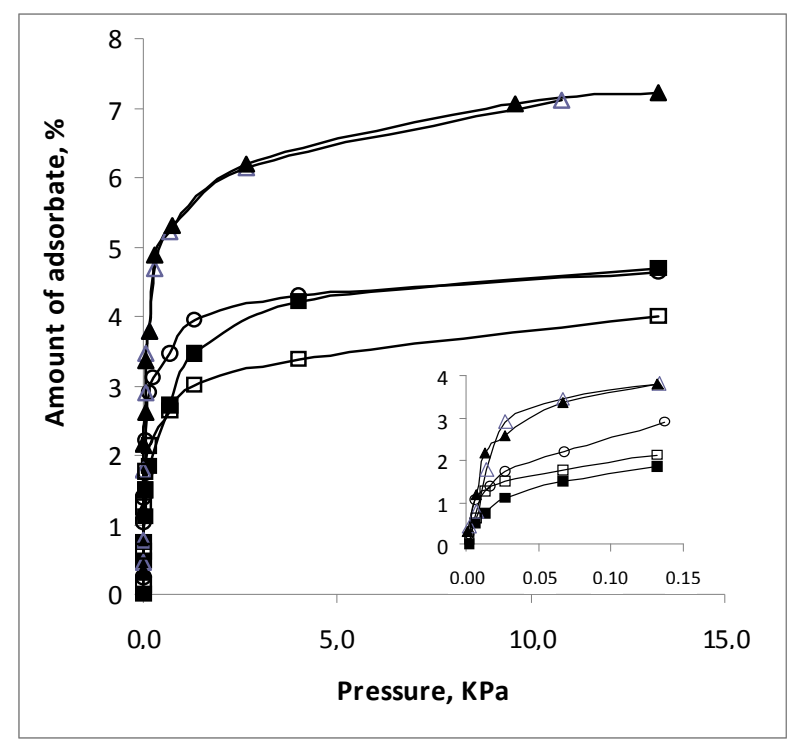

Figure 5. Adsorption isotherms at $298 \mathrm{~K}$ of $\mathrm{n}$-butane $(\mathrm{O})$, ethane $(\Delta)$, ethylene $(\Delta)$, isobutane $(\square)$ and isobutene $(\square)$ on Ferrierite.

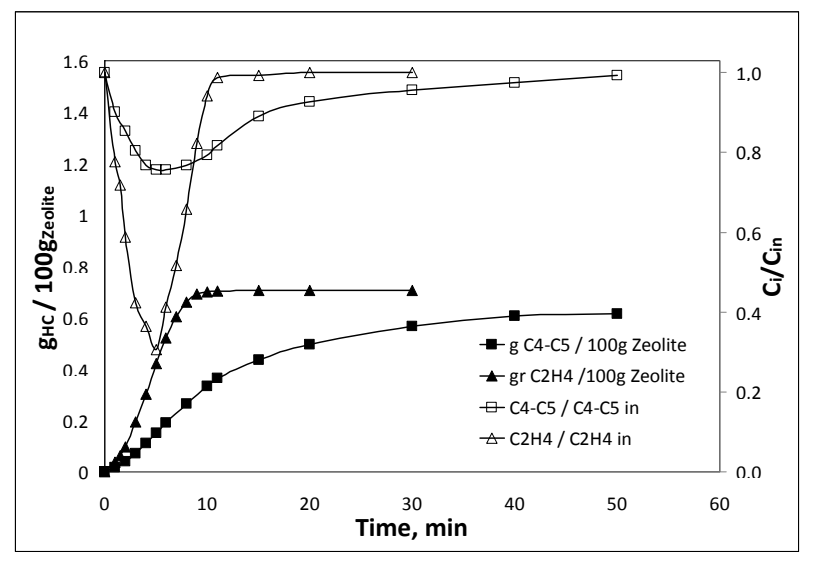

Figure 6. Breakthrough curves (empty symbols) and cumulative adsorption curves (full symbols) at $298 \mathrm{~K}$ for ethylene $(\Delta, \Delta)$ and $\mathbf{C 4}$ - C5 paraffin mixture $(\square, \square)$ on Ferrierite.

Table 2. Equilibrium adsorption capacities at $0.1 \mathrm{kPa}$ and $298 \mathrm{~K}$ obtained by gravimetric tests (gt) and breakthrough curves (bc) for different HCs on $5 \mathrm{~A}$ and Ferrierite, wt $\%$.

\begin{tabular}{ccccc}
\hline & \multicolumn{2}{c}{$5 \mathrm{~A}$} & \multicolumn{2}{c}{ Ferrierite } \\
\hline Ethane & gt & $\mathrm{bc}$ & $\mathrm{gt}$ & $\mathrm{bc}$ \\
Ethylene & 3.13 & - & 3.62 & - \\
n-Butane & 2.92 & 0.05 & 3.58 & 0.70 \\
Isobutane & 3.67 & - & 2.53 & - \\
Isobutene & 1.83 & - & 1.94 & - \\
C4 - C5 paraffins & 1.82 & - & 1.67 & - \\
\hline
\end{tabular}

the absence in the molecule of any permanent dipole moment implies a weaker contribution of coulombic forces to the overall van der Waals interaction [14].

The predominance of this effect seems can explain the adsorption capacity exhibited by $5 \mathrm{~A}$ for $\mathrm{C} 2$ hydrocarbons, while the higher adsorption capacity shown for n-butane can be explained observing that its molecular width (4.9 $\AA$ ) is equal to the maximum value of the kinetic diameter allowed for the molecules to pass through the pores of 5A zeolite [12]. In fact for a larger molecule the enhancement of the interaction energy, due to the overlap of the adsorption field from neighboring walls, can be expected in very fine pores [14].

The breakthrough curves were determined for ethylene and the C4 - C5 hydrocarbon mixture described in Experimental. The first hydrocarbon was selected as representative of light olefins at the engine exhaust, while a paraffin mixture was preferred in dynamic tests to individual compounds in order to verify the adsorption capacity of hydrated zeolites in conditions close to those of a real $\mathrm{HC}$ trap, in terms of space velocity, low partial pressure and simultaneous presence of different compounds.

Figure 4 reports the breakthrough curves obtained for $5 \mathrm{~A}$ zeolite at $298 \mathrm{~K}$ and $30000 \mathrm{~h}^{-1}$, together the values of hydrocarbon cumulative adsorption, calculated as mass of adsorbed $H C$ per $100 \mathrm{~g}$ of zeolite. The formula used for these calculations was the following:

$$
\frac{g_{H C}}{100 g_{\text {zeolite }}}=\sum_{i=1}^{n}\left[\left(C_{i n}-C_{i}\right)\left(t_{i}-t_{i-1}\right)\right] Q M_{\mathrm{C} 3 \mathrm{H} 8} 100
$$

where $C_{\text {in }}$ is the $\mathrm{HC}$ concentration (expressed as C3) at the reactor inlet, $C_{i}$ is the $H C$ concentration at the reactor outlet at the time $t_{i}, Q$ is volumetric flow rate of the gas stream in $\mathrm{nl} / \mathrm{min}, M_{\mathrm{C} 3 \mathrm{H} 8}$ is the molecular weight of propane.

The equilibrium adsorption capacity of $5 \mathrm{~A}$ at $0.1 \mathrm{kPa}$ and $298 \mathrm{~K}$ resulted scarce towards ethylene $(0.05 \%$, see also Table 2), and appreciable for C4 - C5 paraffins $(0.52 \%)$. This selectivity towards paraffins can be attributed to the presence in the mixture of n-butane, as suggested by results of Figure 3. On the other hand, the adsorption values obtained by breakthrough curves resulted very lower with respect to gravimetric tests, in particular the adsorption of ethylene on 5A was almost two order of magnitude lower in dynamic tests $(0.05 \%$ versus $2.92 \%)$. Taking into account that the zeolite micro-channels contained intra-crystalline water molecules during flow adsorption runs (see Experimental), these lower adsorption capacities can be attributed to the competition inside the zeolite micro-channels between intra-crystalline water and $\mathrm{HC}$ adsorbate.

The breakthrough curves of Figure 4 show that the minimum $\mathrm{HC}$ concentration at the bed outlet was de- 
tected after about 5 minutes for C4 - C5 paraffins (about $20 \%$ of trapping capacity), and only after 1 minute for ethylene (for a trapping capacity lower than $10 \%$ ), while the relative bed saturations were reached after about 30 and 10 minutes.

A more interesting applicative result was obtained with Ferrierite zeolite, characterized by a pore opening < $5 \AA$ and $\mathrm{Si} / \mathrm{Al}$ ratio $=10$. The isotherm curves are shown in Figure 5 for $\mathrm{C} 2$ and $\mathrm{C} 4$ hydrocarbons. Microchannel size of Ferrierite determined higher affinity for $\mathrm{C} 2$ compounds than for $\mathrm{C} 4$. In fact, while the saturation adsorption values for $\mathrm{C} 2$ resulted similar to those obtained on 5A zeolite (about 7\%), the value for n-butane was about three time lower (4.2\%), and 3\% - 4\% for ramified C4. The lower capacity shown by Ferrierite for n-butane with respect to $5 \mathrm{~A}$ can be explained invoking the effect of molecular sieving already discussed for ramified $\mathrm{C} 4$ on $5 \mathrm{~A}$.

The magnification of the low pressure zone $(<0.2 \mathrm{kPa})$ reported in Figure 5 (right bottom), together with the values of Table 2, evidences the higher affinity of Ferrierite towards $\mathrm{C} 2$ with respect to $5 \mathrm{~A}$ (about 3.6\% for both ethane and ethylene), while the behavior observed for $\mathrm{C} 4$ on Ferrierite at saturation was confirmed at low partial pressure.

The adsorption measurements in dynamic tests (Figure 6) showed high selectivity of Ferrierite for ethylene $(0.70 \%$ adsorption capacity), while no significant difference for $\mathrm{C} 4$ adsorption was detected between Ferrierite and $5 \mathrm{~A}(0.61 \%$ versus $0.52 \%$ in Table 2$)$.

The best performance of Ferrierite towards ethylene was also confirmed by the high removal efficiency (about 70\%) that can be realized after about 5 minutes of time on stream, to be compared with $8 \%$ of removal efficiency observed on 5A (Figure 4). The breakthrough curve obtained for C4 - C5 paraffins on Ferrierite reproduces the same profile observed on 5A zeolite. The comparison of the breakthrough profiles reported in Figures 4 and 6 evidence a more favorable adsorption kinetic for ethylene with respect to paraffins mixtures on both zeolites investigated, which makes the small pore zeolites, and particularly the Ferrierite, attractive for the removal of light olefins by HC trap technology.

\section{Conclusions}

Adsorption properties of $5 \mathrm{~A}$ and Ferrierite zeolites towards light paraffins and olefins have been investigated at $298 \mathrm{~K}$ by equilibrium isotherms obtained by gravimetric and by dynamic tests in flow microreactor.

The equilibrium isotherms have evidenced an elevated affinity of $5 \mathrm{~A}$ towards n-butane, with a value of saturation adsorption higher than $12 \%$. The adsorption of ethane and ethylene resulted was comparable on the two zeolites, with saturation values comprised between 7 and $8 \%$. Regarding the ramified $\mathrm{C} 4$ hydrocarbons saturation, values of $3 \%-4 \%$ were obtained on both zeolites. At a low partial pressure, some behavior differences were observed for $\mathrm{C} 2$ hydrocarbons, which were adsorbed in higher amounts on Ferrierite (about 20\% more than 5A).

Adsorption capacities obtained with breakthrough curves resulted very lower than the maximum value reachable by gravimetric tests, due to the presence of intra-crystalline water in zeolite samples.

High selectivity for ethylene was observed on Ferrierite, with a removal efficiency of $70 \%$ reached after about 5 minutes of time on stream, while a removal efficiency of only $8 \%$ was observed for ethylene on $5 \mathrm{~A}$ after 2 minutes of time on stream. In spite of this significant difference in removal capacity, both zeolites showed comparable adsorption kinetics. Taking into account the intervenetion times of a TWC catalysts during the start-up phase of gasoline engine (about $120 \mathrm{~s}$ ), the above results suggest that both small pore zeolites investigated could be considered as suitable materials for light olefins removing by $\mathrm{HC}$ trap technology.

\section{REFERENCES}

[1] F. Miano, "Adsorption of Hydrocarbon Vapour Mixtures onto Zeolite 5A," Colloid Surface A: Physicochemical and Engineering Aspects, Vol. 110, No. 1, 1996, pp. 95104. doi:10.1016/0927-7757(95)03439-0

[2] M. J. Ahmed, A. H. A. K. Mohammed and A. A. H. Kadhum, "Prediction of Multi Component Equilibrium Isotherms for Light Hydrocarbons Adsorption on 5A Zeolite," Fluid Phase Equilibrium, Vol. 313, 2012, pp. 165170. doi:10.1016/j.fluid.2011.10.008

[3] T. H. Yeon, H. S. Han, E. D. Park and J. E. Yie, “Adsorption and Desorption Characteristics of Hydrocarbons in Multi-Layered Hydrocarbon Traps," Microporous and Mesoporous Materials, Vol. 119, 2009, pp. 349-355. doi:10.1016/j.micromeso.2008.10.036

[4] P. Eastwood, "Critical Topics in Exhaust Gas Aftertreatment," Research Studies Press, Baldock, 2000.

[5] B. Puertolas, M. V. Navarro, J. M. Lopez, A. M. Mastral and T. Garcia, "Recent Solutions for the Abatement of Hydrocarbon Emissions during the Cold Start of Light Vehicles," Recent Patents on Chemical Engineering, Vol. 4, No. 1, 2011, pp. 36-52.

[6] D. W. Breck, "Zeolite Molecular Sieves," Krieger Publishing Company, Malabar, 1974.

[7] S. Boulard, P. Gilot, R. Brosius, D. Habermacher and J. A. Martens, "Perturbation and Tracer Chromatography Study of Hydrocarbon Adsorption from Simulated Exhaust Gas on Fe-MFI and MOR Type Zeolite Catalysts," Topics in Catalysis, Vol. 30-31, No. 1-4, 2004, pp. 49-53. doi:10.1023/B:TOCA.0000029727.42532.0f

[8] J. H. Park, S. J. Park, I. S. Nam, G. K. Yeo, J. K. Kil and Y. K. Youn, “A Fast and Quantitative Assay for Devel- 
oping Zeolite-Type Hydrocarbon Trap Catalyst," Microporous and Mesoporous Materials, Vol. 101, No. 1-2, 2007, pp. 264-270. doi:10.1016/j.micromeso.2006.11.003

[9] P. Pantu, B. Boekfa and J. Limtrakul, "The Adsorption of Saturated and Unsaturated Hydrocarbons on Nanostructured Zeolites (H-MOR and H-FAU): An ONIOM Study," Journal of Molecular Catalysis A: Chemical, Vol. 277, No. 1-2, 2007, pp. 171-179. doi:10.1016/j.molcata.2007.07.037

[10] L. Song, Z. Sun, L. Duan, J. Gui and G. S. McDougall, "Adsorption and Diffusion Properties of Hydrocarbons in Zeolites," Microporous and Mesoporous Materials, Vol. 104, No. 1-3, 2007, pp. 115-128. doi:10.1016/j.micromeso.2007.01.015

[11] H. Jin, E. A. Prasetyanto, N. Jiang, S. M. Oh and S. E.
Park, "Length Dependency of Hydrocarbon Adsorption on Nanostacked MFI Zeolite by Tracer Chromatography," Applied Surface Science, Vol. 256, No. 17, 2010, pp. 5508-5512. doi:10.1016/j.apsusc.2009.12.125

[12] C. A. Grande, C. Gigola and A. E. Rodrigues, "Dsorption of Propane and Propylene in Pellets and Crystals of 5A, Zeolite," Industrial \& Engineering Chemistry Research, Vol. 41, No. 1, 2002, pp. 85-92. doi:10.1021/ie010494o

[13] Ch. Baerlocher, L. B. McCusker and D. H. Olson, Eds., "Atlas of Zeolite Framework Types," 6th Revised Edition, Elsevier, Amsterdam, 2007.

[14] S. J. Gregg and K. S. W.Sing, "Adsorption, Surface Area and Porosity," Academic Press Inc., San Diego, 1997. 